\title{
ERRATUM
}

\section{Erratum to: Gas around the bladder}

\author{
Chun-Hsiang Yu $\cdot$ Ming-Shian Lin • \\ Che-Hao Hsu • Chi-Yen Liang • Wei Chen
}

Published online: 25 March 2011

(C) SIMI 2011

\section{Erratum to: Intern Emerg Med \\ DOI 10.1007/s11739-011-0547-1}

In the original version of this article, unfortunately reference citation was missed out in text; the corrected text is given below:

The clinical presentation of emphysematous cystitis is nonspecific, and can range from a minimally symptomatic urinary tract infection (UTI) to septic shock. The most common symptom is abdominal pain, and the classic symptoms of UTI have been reported in only approximately $50 \%$ of cases [2]. As symptoms are of no help in reaching a diagnosis, appropriate diagnostic imaging is imperative to establish the diagnosis of EC [2].

The online version of the original article can be found under doi:10.1007/s11739-011-0547-1.

\section{C.-H. Yu}

Department of Internal Medicine,

National Cheng Kung University, Tainan, Taiwan

C.-H. Hsu

Division of Nephrology, Chia-Yi Christian Hospital,

Chiayi, Taiwan

M.-S. Lin · C.-Y. Liang · W. Chen ( $\square)$

Division of Pulmonary and Critical Care Medicine, Chia-Yi

Christian Hospital, 539 Jhongsiao Rd, Chiayi, Taiwan

e-mail: peteralfa2004@yahoo.com.tw

W. Chen

Department of Respiratory Therapy, China Medical University, Taichung, Taiwan

W. Chen

Department of Life Science, National Chung Hsing University, Taichung, Taiwan 